\title{
ALIENAÇÃO PARENTAL: ANÁLISE CRÍTICA DA LEI N. 12.318/2010 E REFLEXÕES SOBRE AS DECISÕES DO TRIBUNAL DE JUSTIÇA DE MINAS GERAIS
}

\author{
PARENTAL ALIENATION: CRITICAL ANALYSIS OF THE LAW N. 12.318/2010 \\ AND REFLECTIONS ON THE DECISIONS OF THE COURT OF MINAS GERAIS
}

\author{
${ }^{1}$ Marcelo de Mello Vieira
}

\section{Resumo}

O presente trabalho visa analisar criticamente o tratamento da Alienação Parental no ordenamento jurídico nacional. Primeiramente, trabalhou-se o Direito à Convivência Familiar de crianças e adolescentes. Posteriormente, definiu-se Alienação Parental, diferenciando-a da Síndrome da Alienação Parental e analisando a opção feita pelo Direito nacional. Examinouse, então, os pontos positivos contemplados pela Lei n. 12.318/2010, como a ampliação dos possíveis alienadores, para depois tratar dos aspectos que o legislador deixou a desejar, como o aspecto punitivo evidenciado pela lei. Por fim, se pesquisou os reflexos da referida legislação nos julgamentos do Tribunal de Justiça de Minas Gerais, analisando-se todas as setenta e nove decisões proferidas.

Palavras-chave: Alienação parental, Criança, Adolescente

\section{Abstract/Resumen/Résumé}

The current paper aims to analyse the approach of Parental Alienation within the national rule of law. First, it deals with the right to living together with family of childs and adolescents. After that, is determined Parental Alienation, distinguishing it from Parental Alienation Syndrome, and analysing the choice of national law. It as then observed the positive aspects of the 12.318/2010 law, as the enhancement of possible alienators, in order to later deal with the aspects that the lawmaker was ineffective, as the punitive aspect highlighted by the law. Finally, is investigated the effects of the referred legislation in the judgments of the Court of Minas Gerais, analyzing all seventy-nine decisions.

Keywords/Palabras-claves/Mots-clés: Parental alienation, Child, Adolescent

\footnotetext{
${ }^{1}$ Doutorando em Direito pela Pontifícia Universidade Católica de Minas Gerais - PUC, Belo Horizonte, MG, (Brasil). Professor na Faculdade de Estudos Administrativos de Minas Gerais, FEAD, Minas Gerais. MG. (Brasil). E-mail.: marcelomvieira@yahoo.com.br
} 


\section{INTRODUÇÃO}

Muitas foram as alterações ocorridas nas famílias desde a metade da segunda década no século XX, tendo sido elas especialmente ocasionadas pela mudança da posição da mulher na sociedade e pela legalização do divórcio. Após a promulgação do texto constitucional de 1988, tais modificações ganharam uma dimensão muito maior. As entidades familiares protegidas pelo Direito, que antes resumiam apenas ao casamento, passaram a ter companhia da União Estável e da família monoparental. O princípio da igualdade passou a reger as relações entre cônjuges e companheiros e as relações filiais e a paternidade responsável foi elevada a categoria de princípio constitucional. Com isso, reforçou-se o papel dos pais no exercício da maternidade/paternidade, evidenciando a necessidade de uma participação ativa de ambos na vida dos filhos.

Nesse contexto, situações que aconteciam na vida real, especialmente em ações de separação ou divórcio litigioso ou de disputa de guarda de crianças, que prejudicavam relação entre pais e filhos, deixaram de ser invisíveis e passaram a ser discutidas. A Alienação Parental é uma dessas situações. De desconhecida e invisibilizada, ela ganhou destaque no mundo jurídico e o debate sobre seus efeitos se intensificou nos últimos anos, culminando com o advento da Lei n. 12.318/2010. Se em vários aspectos esse diploma representou um ganho para o combate a essa verdadeira violação ao Direito à Convivência Familiar de crianças e adolescentes (art. $3^{\circ}$ ), em outros se mostrou frágil para efetivamente se tratar a Alienação Parental.

O presente trabalho se destina a analisar criticamente alguns pontos da Lei $n$. 12.318/2010 apontando as vantagens e as fragilidades da legislação. Para tanto, trabalhar-se-á o Direito à Convivência Familiar de crianças e adolescentes, buscando trazer os contornos desse importante direito. A diferenciação entre Alienação Parental e Síndrome da Alienação Parental será tratada em seguida e se examinará os motivos pelos quais o legislador pátrio optou por trabalhar a primeira ao invés da segunda. Posteriormente, examinar-se-ão os aspectos positivos da lei, bem como aqueles que o legislador deixou a desejar. Por fim, serão analisados criticamente os julgados do Tribunal de Justiça de Minas Gerais que expressamente mencionam a Alienação Parental.

\section{DIREITO À CONVIVÊNCIA FAMILIAR DE CRIANÇAS E DE ADOLESCENTES}


A Constituição da República Federativa do Brasil de 1988 (CRFB/1988) inaugurou um novo paradigma jurídico no tratamento de crianças e adolescentes no direito nacional. Até então, o Direito brasileiro tratava os menores de duas formas distintas: àqueles que viviam com as famílias que atendiam aos "padrões sociais" da época, eram considerados menores em situação regular e a eles aplicavam-se as normas do Código Civil, enquanto aqueles que não viviam com suas famílias ou cujas famílias não atendiam as expectativas da sociedade eram denominados de menores em situação irregular ${ }^{1}$, sendo a eles imposta a dureza do Código de Menores de 1979 (NERY JUNIOR; MACHADO, 2013).

Adiantando-se a promulgação da Convenção Internacional dos Direitos da Criança de 1989, o texto constitucional garante prioridade absoluta à efetivação dos Direitos da Criança e do Adolescente, assegurando a toda população infantojuvenil, sem distinção, os mesmos direitos e garantias individuais e sociais aos adultos nos artigos $5^{\circ}$ e $6^{\circ}$ e outros direitos próprios da condição de pessoa em desenvolvimento como o direito ao respeito e à convivência familiar e comunitária (art. 227) ${ }^{2}$.

Para Tânia da Silva Pereira (2008), o artigo 227 da CRFB/1998 marca a adoção da Doutrina da Proteção Integral pelo direito pátrio e, por esta razão as crianças e os adolescentes deixam de ser vistos como objetos da intervenção do Estado e passam a ser tratadas como sujeitos de direitos. Como isso, o termo "menor" que, ao longo do tempo, ganhou uma carga pejorativa foi substituído pelas expressões criança e/ou adolescente ${ }^{3}$, termos destituídos de qualquer aspecto valorativo. Essa doutrina, que passou a embasar o tratamento à população infantojuvenil no país, é chamada de Proteção Integral porque ela visa a atender todas as

\footnotetext{
1 O Código de Menores de 1979 era fundado na excludente Doutrina da Situação Irregular e enunciava taxativamente, em seu art. $2^{\circ}$, as situações nas quais os menores estariam em situação irregular. Assim, aquele que era privado de condições essenciais à sua subsistência, saúde e instrução obrigatória, ainda que eventualmente, em razão da falta, ação ou omissão dos pais ou responsável ou da manifesta impossibilidade dos pais ou responsável para provê-las; que era vítima de maus-tratos ou castigos imoderados impostos pelos pais ou responsável, bem como quem que estava em perigo moral, devido a encontrar-se, de modo habitual, em ambiente contrário aos bons costumes ou a exploração em atividade contrária aos bons costumes (art. $2^{\circ}$ I, II e III). Também se consideravam em situação irregular, os menores privados de representação ou assistência legal, pela falta eventual dos pais ou responsável; os que estavam em desvio de conduta, em virtude de grave inadaptação familiar ou comunitária e os autores de infração penal ( $\operatorname{art.} 2^{\circ} \mathrm{IV}, \mathrm{V}$ e VI).

${ }^{2}$ Além do direito ao respeito e à convivência familiar e comunitária, o art. 227 da CRFB/1988 ainda explicita o direito à vida, à saúde, à alimentação, à dignidade, à cultura, à profissionalização, à liberdade, à educação e ao lazer.

${ }^{3}$ Fernando Londoño (1996) afirma que até o século XIX, menor significava criança e adolescente, mas posteriormente passou a ser identificada com os delinquentes e abandonados.
} 
necessidades da criança (saúde, educação, lazer, etc.) em todos os aspectos de sua vida (físico, mental, espiritual, etc.) durante o período da infância e da adolescência. Tal pretensão exige necessariamente uma atuação transdisciplinar e cooperativa de vários profissionais das mais variadas especialidades.

O artigo 227 da CRFB/1988 ainda previu que nenhuma criança e adolescente será vítima de negligência, discriminação, exploração, violência, crueldade ou opressão, garantia esta reforçada pelo art. $5^{\circ}$ do Estatuto da Criança e do Adolescente (Lei n. 8.069/1990). O mesmo Estatuto, em seu art. $3^{\circ}$, dispõe que a lei ou outros meios assegurarão todas as oportunidades e facilidades, a fim de facultar o desenvolvimento físico, mental, moral, espiritual e social das crianças e adolescentes.

Dentre os direitos fundamentais previstos para a população infantojuvenil, no artigo 227 do texto constitucional, alguns deles são expressamente consagrados no ordenamento jurídico nacional pela primeira vez. Tais direitos não são resultantes de uma longa construção teórica e jurisprudencial, eles simplesmente "aparecem" no direito pátrio, razão qual ainda hoje não possuem seus contornos bem delimitados (VIEIRA, 2012, p. 135). É o que acontece com o Direito à Convivência Familiar ${ }^{4}$.

Maria Berenice Dias (2007) utiliza o termo "direito de convivência" como sinônimo de "direito de visitação". Em que pese o entendimento exposto, esse não parece traduzir a completude direito.

A CRFB/1988 inaugurou um novo paradigma para o direito da infância e da juventude, criando todo um sistema dedicado à proteção e a promoção dos direitos da criança e do adolescente. Nesse contexto, reduzir a convivência familiar à mera presença física não nos parece fazer jus à importância atribuída às pessoas em desenvolvimento. A simples leitura dos dispositivos que detalham o Direito à Convivência Familiar constantes no Estatuto da Criança e do Adolescente ${ }^{5}$ (art. 19 a 52-D) já indica que este direito vai muito além da relação pais e filhos ou avós e netos, inclusive prevendo as formas que ele pode ser efetivado em família substituta (guarda, tutela ou adoção).

Portanto, o Direito à Convivência Familiar deve ser visto como um direito de toda

\footnotetext{
4 Ana Carolina Teixeira chega a indagar qual “a extensão do direito fundamental à convivência familiar?". (TEIXEIRA: 2008b, p. 307).

5 É importante destacar que embora mencionado no Estatuto do Idoso, na Lei Maria da Penha e, recentemente, no Estatuto da Pessoa com Deficiência, o único diploma normativo que de fato esmiúça o Direito à Convivência Familiar é o Estatuto da Criança e do Adolescente.
} 
criança e/ou adolescente em ser efetivamente inserido na vida de uma família, com a finalidade de promoção de sua personalidade e de se sentir parte de uma família, tendo suas opiniões consideradas, participando da vida familiar. É também o direito de serem educados em um ambiente que lhes possibilite o seu desenvolvimento. O contato ou visitação é apenas parte desse direito muito mais abrangente. Essa visão mais abrangente seria a única capaz de realmente proteger todas as pessoas em desenvolvimento.

A Lei n. 12.318/2010, que poderia ter contribuído para melhor delimitar este direito, serviu para aumentar a dúvida. Isso porque o inciso III do artigo $2^{\circ}$ da lei definiu como um ato de alienação parental dificultar o contato da criança com o seu genitor, enquanto o inciso IV do mesmo dispositivo previu também como conduta alienadora dificultar o exercício do direito à convivência familiar regulamentado. A partir da análise destes incisos, as expressões "direito ao contato" e "direito à convivência familiar" não podem possuir o mesmo significado. Do contrário, o inciso IV seria completamente inútil. Contudo, a palavra "regulamentado" e a previsão do art. $6^{\circ}$ II da Lei de alienação parental (possibilidade de ampliação do regime de convivência familiar em favor do genitor alienado) lembram regime de visitação. Esse raciocínio é reforçado pelo parágrafo único do mesmo art. $6^{\circ 6}$. No entanto, conforme já salientado igualar as expressões não parece coadunar com o tratamento dado aos direitos da infância e juventude.

Partindo dessa noção mais ampla baseada nas disposições da Lei n. 8.069/90, podese afirmar que o Direito à Convivência Familiar objetiva:

[...] assegurar que toda a criança e adolescente tenha um ambiente propício para a formação de sua personalidade. Embora todo o ser humano esteja em constante desenvolvimento de sua personalidade, é na infância e na adolescência, justamente por sua condição especial, que ele precisa de maior proteção. (VIEIRA, 2012, p. 137).

Inegavelmente, o Direito à Convivência Familiar deve ser garantido em sua família natural - comunidade formada pela criança e seus pais (art. 25 da Lei n. 8.069/90) e subsidiariamente em família extensa - aquela formada pelos parentes próximos ligados à criança ou ao adolescente pela convivência e laços de afetividade e afinidade (art. 25 parágrafo único da Lei n. 8.069/90) - ou em família substituta - aquela que não é família natural ou extensa - nessa ordem.

\footnotetext{
${ }^{6}$ - Lei 12.318/2010. Art. $6^{\circ}$ (...) Parágrafo único. Caracterizado mudança abusiva de endereço, inviabilização ou obstrução à convivência familiar, o juiz também poderá inverter a obrigação de levar para ou retirar a criança ou adolescente da residência do genitor, por ocasião das alternâncias dos períodos de convivência familiar.
} 
Independentemente de a família garantidora do Direito à Convivência Familiar ser natural, extensa ou substituta, o importante é que ela seja o "espaço primário e essencial de desenvolvimento da personalidade da pessoa humana, sendo sede das relações íntimas e privadas de seus membros.” (MILAGRES, 2008, p. 212-213). Entretanto, em algumas situações esse direito pode ser violado ou obstaculizado dentro dessa relação familiar pelas ações daqueles que justamente deviam zelar por ele. A alienação parental é um exemplo.

\section{ALIENAÇÃo PARENTAL (AP) E SINDROME DA ALIENAÇÃo PARENTAL} (SAP)

Após anos trabalhando com casos de guarda de filhos, em 1985, o psiquiatra americano Richard Gardner identificou um tipo transtorno psíquico que aparecia com alguma frequência e ele a denominou Síndrome da Alienação Parental (SAP) ${ }^{7}$. Ela pode ser conceituada como a "a situação em que a mãe ou o pai de uma criança a treina para romper os laços afetivos com o outro genitor, criando fortes sentimentos de ansiedade e temor em relação ao outro genitor". (SAP, 2105, grifo no original). Trata-se de uma patologia consistente em um processo destrutivo e desmoralizante no qual o alienador busca acabar com a imagem que a criança ou adolescente tem de um dos pais e a confiança que tem nele, sendo seu objetivo maior, manipular a criança para que ela exclua o genitor alienado da sua vida.

A Síndrome da Alienação Parental não se confunde com a Alienação Parental (AP). Filipa de Carvalho (2011) assevera que o próprio Gardner via necessidade em distinguir SAP de AP e ensina que para o psiquiatra:

[...] enquanto a SAP se consubstancia num conjunto de comportamentos e acções desenvolvidas por um dos progenitores sobre os menores de forma a controlar a relação entre eles e o progenitor alienado e, paulatinamente, a afastá-los, criando nos menores uma atitude de repulsa e rejeição relativamente a este progenitor, a alienação parental constitui, por si só, um termo genérico que abrange não só os casos de abuso emocional, presente nos casos de SAP, mas também situações de abuso psicológico $^{8}$. (sic) (CARVALHO, 2011, p. 54-55).

Logo se percebe que a Alienação Parental é mais ampla que a Síndrome de Alienação Parental, não sendo também uma patologia e que, como consequência, só poderia ser reconhecida com pela Medicina ou pela Psicologia e não exclusivamente pelo Direito. Para Filipa de Carvalho (2011), embora seja valorosa a participação de especialistas de saúde, 
a AP permite que uma análise direta e apenas jurídica do magistrado, enquanto a SAP obrigaria o juiz a entrar nas searas medico-psicológicas, as quais os julgadores dificilmente têm conhecimento aprofundado?

Com a divulgação da SAP, especialmente na psicologia e psiquiatria, ela chamou atenção do mundo jurídico e discussões sobre sua ocorrência nos feitos que tramitavam nas varas de família começaram de forma tímida ${ }^{10}$ e aos poucos ganhou força, culminando com o advento da Lei n. 12.318/2010 dedicada com combate da Alienação Parental.

A clara opção do legislador brasileiro foi pelo acolhimento da Alienação Parental em detrimento da Síndrome da Alienação, o que vai ao encontro da Proteção Integral da Criança e do Adolescente, uma vez que proporciona uma proteção mais abrangente, já que a AP englobaria a SAP, não sendo verdadeiro o contrário.

\section{APONTAMENTOS SOBRE A LEI N. 12.318/2010.}

Apesar de ser possível depreender que o sistema jurídico nacional implicitamente já protegia a população infantojuvenil da Alienação Parental, a promulgação de uma lei específica, em 2010, foi de grande importância para por o tema em evidência, chamando atenção da sociedade e do judiciário para a necessidade de se prevenir e combater a AP. Nesse sentido, é inegável que ela possui um destacado papel simbólico. No entanto, a mera edição da lei não pode ser vista como a solução para o problema (GONDIN, 2015), sendo, na verdade, muito mais o ponto de partida para se discutir possíveis respostas a essa situação não incomum.

A lei inova o direito brasileiro, dando maior concretude a essa proteção, porém ela possui alguns aspectos louváveis, enquanto outros bem discutíveis, ambos merecendo igual destaque.

\footnotetext{
7 Há um sítio na internet que busca esclarecer e combater a alienação parental. O que é SAP? http://www.alienacaoparental.com.br/o-que-e.

${ }^{8}$ No mesmo sentido, Maria Antonieta Motta afirma que "SAP constitui-se em verdadeira forma de abuso psicológico contra crianças e adolescentes que são a ele submetidos.” (grifo no original) (MOTTA, 2008, p. 36).

${ }^{9}$ Frederick Gondin (2015) defende que a utilização de Alienação Parental ao invés de Síndrome da Alienação Parental causa prejuízos uma vez que não se conseguiria identificar o causador da SAP e, portanto, este ficaria impune. Em que pese a opinião do autor, não há, à priori, de se falar em alguns tipo de prejuízo e sim e
} 


\subsection{ALIENAÇÃO PARENTAL PARA O ORDENAMENTO JURÍDICO BRASILEIRO}

$\mathrm{O}$ artigo $2^{\circ}$ da Lei n. 12.318/2010 define a Alienação Parental como toda interferência na formação psicológica infantojuvenil capaz de promover ou induzir sentimentos de repulsa ou que prejudique a criação ou preservação de vínculos entre algum dos pais com o(s) filho(s).

O principal elemento caracterizador é, portanto, a interferência do alienador na relação paterno-materno filial, sendo que tal ingerência pode se dar das mais variadas formas. A não comunicação de fatos importantes da vida do filho (mudança de escola, consultas médicas); a constante expressão de desabono das condutas e da personalidade do genitor e o uso da criança para transmitir recados ao alienado são formas comuns e veladas de alienação parental. Já o controle excessivamente rígido dos horários de visita; a marcação de atividades de interesse da criança para os dias de visitação e críticas e destruição de presentes dados pelo alienado ao filho até a realização de falsas denúncias de abuso sexual e de uso de substâncias proibidas apresentam-se como formas mais agressivas.

O parágrafo único do mesmo art. $2^{\circ}$ da Lei n. 12.318/2010 traz um rol exemplificativo de condutas que seriam consideradas alienação parental. São sete hipóteses, sendo que o inciso I (realizar campanha de desqualificação da conduta do genitor em relação a maternidade/paternidade) e o inciso II (dificultar o exercício do poder familiar) sintetizam todas as condutas. De acordo com Walsir Rodrigues Junior e Renata Almeida (2010) a definição enunciativa visa dar ao julgador maior segurança para identificar e promover, de forma célere, medidas para combater a alienação parental.

Por outro lado, para a configuração da Alienação Parental não basta só a interferência. Se esta ocorrer em benefício da criança, a conduta é não só legal, como necessária. A influência alienadora é aquela capaz de induzir, na criança, sentimentos de rejeição, raiva, abandono ou até mesmo de descaso em relação ao(s) genitor(es).

\footnotetext{
benefícios, uma vez que a AP combateria a SAP, bem como outras condutas também prejudiciais ao desenvolvimento infantojuvenil.

${ }^{10}$ Uma das primeiras decisões que versaram sobre o tema foi proferida em 07 de junho de 2006 pelo Sétima Câmara Cível do Tribunal de Justiça do Rio Grande do Sul no julgamento do Agravo de Instrumento $\mathrm{N}^{\mathrm{o}}$ 70014814479 de relatoria da Desembargadora hoje aposentada Maria Berenice Dias que expressamente reconheceu indícios de Síndrome da Alienação Parental.
} 
A ausência de uma relação sadia com os genitores pode causar à criança ou ao adolescente baixa autoestima, depressão, ansiedade e até dificuldade em estabelecer relações duradouras no futuro, causando prejuízos à formação da personalidade da criança. Logo, pode-se afirmar que a grande vítima da AP é, sem dúvida, a criança, vez que, em razão de ainda estar em fase de desenvolvimento, é aquela que menos possui meios de se defender (HIRONAKA, MONACO, 2011, p. 245).

A Alienação Parental é, portanto, um desrespeito não só ao direito fundamental infantojuvenil à convivência familiar saudável, como dispõe o artigo $3^{\circ}$ da Lei n. 12.318, mas viola também muitos dos direitos da personalidade da criança e/ou adolescente.

\subsection{CAUSADORES E CAUSAS: AMPLIANDO A PROTEÇÃO A CRIANÇA E AO ADOLESCENTE OU OS AVANÇOS DA LEI N. 12.318/2010.}

Apesar de ter sido inicialmente identificada em casos em que se discutia guarda e visitação de filhos após o fim da sociedade conjugal, o legislador brasileiro entendeu, por bem, ampliar o rol de possíveis autores da Alienação Parental incluindo também os avós e todos aqueles que tenham a criança ou o adolescente sob guarda, autoridade ou vigilância ${ }^{11}$ (art. $2^{\circ}$ Lei n. 12.318/2010). A inclusão de outras pessoas como possíveis alienadores tem somente a contribuir para que essa prática seja efetivamente coibida por quem quer que a utilize. Walsir Júnior e Renata Almeida (2010) entendem que esta ampliação é uma das mais importantes emendas feitas ao projeto.

$\mathrm{O}$ artigo $3^{\circ}$ da Lei n. 12.318/2010 pontua que os atos de Alienação Parental são violações ao direito fundamental de convivência familiar saudável da criança ou do adolescente, constituindo abuso moral contra essas pessoas em desenvolvimento, além de ser um descumprimento dos deveres inerentes à autoridade parental ou decorrentes de tutela ou guarda.

Se por um lado a AP sempre será uma lesão ao Direito à Convivência Familiar (desde que se entenda este direito como trabalhado no tópico 2), ela nem sempre será um abuso de poder familiar ou dos deveres decorrentes da tutela ou guarda. Isso porque, conforme dispõe o Código Civil de 2002 (CCB/2002), somente os pais são detentores do poder familiar (autoridade parental, segundo a Lei 12.318/2010). Assim sendo, somente há de se falar em abuso ou descumprimento de deveres do poder familiar quando o alienador for um dos genitores. Todavia, como já visto, o rol de pessoas capazes de perpetrar a alienação 
parental deve ser o mais amplo possível, uma vez que somente assim será capaz de garantir que nenhuma criança ou adolescente será vítima desta forma de violência e opressão. É neste sentido que o projeto de lei original foi alterado, dando origem a redação do artigo $2^{{ }^{12}}$.

Tanto a guarda quanto a tutela necessitam de deferimento judicial. Sobre o descumprimento dos deveres de guarda é necessário recordar que nem sempre quem detém a guarda é um dos genitores, já que no direito pátrio além da guarda de filhos, a guarda também poderá ser uma medida de colocação em família substituta, seja ela família extensa ${ }^{13}$ ou não (Lei n. 8.069/1990 art. 28 e 33 e seguintes). Deve-se ressaltar também que mesmo quem não detém guarda pode ser alienador, não se podendo em tal situação de se falar em descumprimento de nenhum dever inerente à autoridade parental, guarda ou tutela. É o caso do avô que denigre a imagem dos pais, mesmo não tendo a guarda.

Contudo, em muitos casos, haverá sim um abuso moral dos deveres inerentes ao poder familiar ou à guarda e, independentemente, de quem seja o alienador, haverá ato ilícito.

A menção à tutela é, no mínimo, curiosa. Isto porque a tutela pressupõe a ausência de poder familiar, seja pelo falecimento ou pela decretação de ausência dos pais ou pela destituição do poder familiar, conforme art. 1.728 do CCB/2002. Dessa forma, havendo tutela não há interferência no convívio entre pais e filhos, já que este seria impossibilitado pela morte ou por decisão judicial.

Embora seja sabido que crianças e adolescentes necessitam de vínculos psicológicos estáveis e duradouros não só com seus familiares, mas também com todos aqueles cujo contato é positivo para criança - amigos, professores, etc. - (MOTTA, 2008, p. 37) é importante esclarecer que a apenas os possíveis alienadores foram ampliados, sendo que o alienado necessariamente deve ser um dos pais.

\footnotetext{
${ }^{11}$ A redação do citado artigo trata-se de um substitutivo ao projeto original feito pelo Deputado Pastor Pedro Ribeiro (PDC-CE). No projeto inicial, somente os pais poderiam ser alienadores.

${ }^{12}$ Lei n. 12.3318 - Art. $2^{\circ}$ Considera-se ato de alienação parental a interferência na formação psicológica da criança ou adolescente, promovida ou induzida por um dos genitores, pelos avós ou pelos que tenham a criança ou adolescente sob sua autoridade, guarda ou vigilância, para que repudie genitor ou que cause prejuízos ao estabelecimento ou à manutenção de vínculos com este. (BRASIL, 2010).

13 A Lei 12.010/2010 acrescentando o parágrafo único no art. 25 do Estatuto da Criança e do Adolescente conceituou família extensa como "aquela que se estende para além da unidade pais e filhos ou da unidade do casal, formada por parentes próximos com os quais a criança ou adolescente convive e mantém vínculos de afinidade e afetividade".
} 
Maria Berenice Dias (2015) afirma que a não elaboração do luto da separação pode fazer com que aquele que se sinta traído, rejeitado ou abandonado passe a desmoralizar e desacreditar o ex-cônjuge, buscando se vingar afastando o genitor do filho, caracterizando a SAP. A autora afirma também que o alienador chega até mesmo a sentir prazer em promover esse processo difamatório (DIAS, 2015). Na mesma linha, Filipa de Carvalho (2011) afirma que a Síndrome da Alienação Parental, na maioria das vezes, é ligada ao sentimento de rejeição e na incapacidade do genitor em superar tal situação sem envolver a prole, muitas vezes usando os filhos como meio de vingança. Já para Maria Antonieta Motta (2008), vários são os motivos que levam alguém iniciar a SAP:

\begin{abstract}
Alguns podem estar cegos por sua raiva, ou ciumentos ao constatar que seu excônjuges encontra-se em nova relação amorosa. Se ele não tiver também um par, pode sentir que os filhos são a únicas coisas que lhe restam. A sua cólera pode também ser provocada por fatores econômicos que envolvem inveja do genitor alienado" em relação à condição do genitor alvo, ou ressentimento por ter perdido as benesses que usufruía na vigência do casamento, e não propriamente um desentendimento deste às necessidades dos filhos. (MOTTA, 2008, p.38)
\end{abstract}

Todavia, o mencionado artigo $2^{\circ}$ da Lei n. 12.318/2010 não faz nenhuma referência ao rompimento da sociedade conjugal. Dessa forma, a referida lei é aplicável tanto quando houver ou não existir mais uma relação conjugal (casamento ou união estável), bem quando nas hipóteses em que essa sociedade nunca (namoro ou até mesmo encontros fugazes), ou seja, para o direito nacional, a Alienação Parental deve ser combatida não há a separação ou o divórcio dos pais.

A assistente social Maria Valente (2008), valendo-se de sua experiência nas Varas de Família, reforça tal ideia, afirmando que a SAP pode ocorrer em situações que vão desde a ruptura de uma sociedade conjugal marcada pela violência entre os pais, nas quais geralmente o genitor guardião muda-se sem deixar contato ou com a obstaculização do convívio, quando o pai guardião não permite o contato com o parceiro amoroso daquele não guardião ou até com a interferência dos avós que passam a fazer o papel de pais, em razão da pouca idade dos genitores ou falta de afinidade entre eles.

Nesse contexto, parece mais acertado o entendimento defendido por Evandro Silva e Mário Resende (2008) que asseveram que Alienação Parental não surge com o rompimento da sociedade conjugal "que são comportamentos que remetem a uma estrutura psíquica já construída, manifestando-se de forma patológica quando algo sai do seu controle." (SILVA, RESENDE, 2008, p. 27). O fim do casamento ou da união estável poderia ser um "gatilho" 
que daria início ao comportamento alienador, mas não o único. É só lembrar que a lei visa combater a AP em qualquer situação e que reduzi-la as situações que envolva a existência prévia de uma sociedade conjugal, dificultaria esse intento.

A Alienação Parental também se configura independentemente da consciência do alienador de que seus atos estão dificultando o convívio da criança/adolescente com o genitor, bastando que seu comportamento seja nocivo à formação psicológica da criança, prejudicando os vínculos afetivos entre pai/mãe e filho.

\subsection{INSTRUMENTOS PREVISTOS NA LEI 12.318/2010 PARA COIBIR A ALIENAÇÃO PARENTAL OU ONDE PODE TER SE AVANÇADO MAIS.}

A Lei $12.318 / 2010$, em seu art. $6^{\circ}$, além da possibilidade de responsabilização civil e penal, previu sete medidas a ser utilizadas pelo magistrado de forma isolada ou cumulativa, quando ficar caracterizado atos de alienação parental ou qualquer outra conduta dificultadora do convívio entre pais e filhos. Ao trazer expressamente medidas a serem utilizadas nos casos de AP, o legislador facilita a atuação do julgador, chamando a atenção deste para os mecanismos a serem considerados aptos a lidar com a Alienação Parental, ao mesmo que serve como um "alerta" a todos possíveis alienadores sobre as consequências de seus atos. Tais medidas vão desde a advertência; passando pela mudança ou ampliação do regime de guarda, multa ou intervenção psicológica chegando até a suspensão do poder familiar. No entanto, mesmo antes da referida lei o direito pátrio já contava com instrumentos para prevenir e coibir a Alienação Parental.

Considerando que a AP é uma violação de um direito fundamental da criança e do adolescente, conforme reconhece o artigo $3^{\circ}$ da Lei n. 12.318/2010, ela poderia ser enquadrada como uma situação de risco prevista no art. $98^{14}$, II da Lei n. 8.069/1990. Assim sendo, estaria legitimada a aplicação das medidas protetivas pertinentes constantes no artigo 101 do Estatuto da Criança e do Adolescente, como a orientação e acompanhamento temporário (II), a requisição de tratamento psicológico ou psiquiátrico (V) até a colocação em família substituta, em casos extremos como quando ambos os pais perpetrarem a Alienação Parental (IX). Para os pais ou responsáveis poderia ensejar a aplicação das medidas no artigo 129 da Lei n. 8.069/1990, como o encaminhamento dos pais ou responsáveis a tratamento psicológico ou psiquiátrico (III), a advertência (VII), perda da guarda (VIII) ou até mesmo a suspensão ou destituição do poder familiar $(\mathrm{X})^{15}$. 
Ressalte-se que a maioria destas medidas pode ser aplicada tanto judicialmente quanto pelos conselhos tutelares e estes, se qualificados, poderiam tornar-se um especial órgão de combate a Alienação Parental.

Haveria, também, possibilidade de aplicação de sanção pecuniária, já que a AP poderia ser enquadrada como descumprimento doloso ou culposo dos deveres inerentes ao poder familiar ou a guarda, tendo o artigo 249 do Estatuto da Criança e do Adolescente previsto a penalidade de três a vinte salários mínimos, aplicando o dobro no caso de reincidência para esta infração administrativa. No entanto, esta sanção só poderia ser aplicada quando o alienador for um dos pais ou guardião.

Como já dito, a aplicação de tais medidas era possível com base na Lei n. 8.069/1990, sendo a real inovação da Lei n. 12.318/2010, a extensão da aplicação das mesmas aos avós ou àqueles que tenham as crianças e adolescentes sob sua autoridade ou vigilância e possibilidade de fixação de um domicilio para a criança quando o alienador se mudar reiteradas vezes e sem justificativa de residência $\left(\right.$ art. $\left.6^{\circ}\right)$.

Contudo, a lei deixou a desejar ao prever medidas apenas punitivas, enquanto o foco deveria ser a prevenção da Alienação Parental e o tratamento de tais situações de modo a proporcionar uma nova relação entre os envolvidos e não a mera punição.

Maria Berenice Dias (2015), Rosane Simão (2008) e Frederick Gondin (2015) defendem a necessidade da reprimenda estatal com o intuito de coibir a AP. Porém, parece que os autores se esquecem que a relação entre criança ou adolescente, alienante e genitor alienador será uma relação duradoura, podendo as sanções aplicadas acirrar ânimos e inibir o alienante apenas a praticar os atos de Alienação Parental na frente de terceiros. Para Maria Azambuja, Lisieux Telles e Vivian Day o reconhecimento da "alienação parental através de decisão judicial contribuirá muito mais para reforçar do que para resolver a disfunção apresentada pela família." (AZAMBUJA; TELLES; DAY, 2015). Ressalte-se que a aplicação cega de algumas medidas, como a alteração ou a inversão da guarda ou a suspensão do poder familiar, em diversas ocasiões pode ser prejudicial à criança mesmo ocorrendo a AP.

\footnotetext{
${ }^{14}$ Lei n. 8.069/1990 - Art. 98. As medidas de proteção à criança e ao adolescente são aplicáveis sempre que os direitos reconhecidos nesta Lei forem ameaçados ou violados:

(...) II - por falta, omissão ou abuso dos pais ou responsável.

${ }^{15}$ Nesse aspecto, o art. 129 da Lei n. 8.069/1990 seria até mais duro que a Lei n. 12.318/2010, uma vez que poderia ensejar a destituição do poder familiar, enquanto o art. $6^{\circ}$ da lei de combate a Alienação Parental permitiria no máximo a suspensão do mesmo poder familiar (art. $6^{\circ}$ VII).
} 
Embora a Lei n. 12.318/2010 tenha previsto a necessidade da atuação da equipe interdisciplinar, o papel a ela atribuído é unicamente de perito psicológico ou biopsicossocial, ou seja, a atuação desses profissionais se voltaria mais a produção de provas, inclusive para subsidiar as ações de responsabilidade civil, do que propriamente diagnosticar a alienação parental e permitir o tratamento dos envolvidos.

A atuação de uma equipe interprofissional já ocorre tanto nas Varas de Família, quanto nas Varas da Infância e da Juventude e a intervenção desta equipe nas ações de guarda de crianças e adolescentes, bem como nas ações de dissolução de união estável, de separação ${ }^{16}$ ou divórcio litigioso poderia ser de grande valia para auxiliar o magistrado tanto na definição do regime de guarda e visitação, como para identificar a propensão de algum dos genitores à prática de alienação parental. Para Rosana Simão:

\begin{abstract}
Mediante uma atuação interdisciplinar dos profissionais das áreas jurídicas, sociais e psicológicas devem-se buscar a prevenção e a pronta reparação da violação dos direitos dos filhos, sob pena de fazer letra morta as previsões normativas existentes para proteção dos seres humanos em formação. (SIMÃO, 2008, p. 16).
\end{abstract}

O legislador, portanto, ignorou qualquer papel preventivo à Alienação Parental que as equipes interdisciplinares poderiam ter, preferindo crer que a punição por si só seria capaz de acabar com a AP.

Como já tratado, a Alienação Parental afeta um relação que é duradoura (relação paterno-filial) e se não trabalhados os fatores que motivam a atuação do alienador, dificilmente se reestabelecerá uma relação saudável. Na maioria das vezes, o alienador é “incapaz de ver a situação de outro ângulo que não o seu e especialmente o ponto de vista e interesse dos filhos são ignorados.” (MOTTA, 2008, p. 38). Para Silva e Resende (2008), isso se dá porque o alienador fica tão emocionalmente comprometido que percebe o prejuízo que provoca à criança ou ao adolescente. O processo judicial, embora dê uma resposta jurídica para situação, frequentemente não trabalha as questões que estão por trás da AP e, por vezes, tende a afastar ainda mais o genitor alienado, que se sente colocado em segundo plano, havendo entre ele e seu filho a poderosa figura do juiz (BOLAÑOS CARTUJO, 2000).

\footnotetext{
${ }^{16}$ Após a Emenda Constitucional n. 66 passou a existir um debate sobre a possibilidade ou não de novas ações de separação judicial no país.
} 
Os métodos complementares de solução de conflitos poderiam ser uma alternativa para o tratamento da Alienação Parental, porque eles utilizam uma metodologia baseada no diálogo, na qual uma parte pode mostrar para a outra as implicações de cada ato, além de possibilitar a efetiva participação da criança e do adolescente, tudo isso com o intuito de se construir compartilhadamente uma decisão que efetivamente atenda os interesses dos envolvidos. A mediação é um dos meios disponíveis para se tratar esse conflito. Nas palavras de Walsir Júnior e Renata Almeida, ela seria:

[...] o processo dinâmico que visa ao entendimento, buscando desarmar as partes envolvidas no conflito. O mediador, terceiro neutro e imparcial, tem a atribuição de mover as partes da posição em que se encontram, fazendo-as chegar a uma solução aceitável. A decisão é das partes, tão somente delas, pois o mediador não tem poder decisório nem influencia diretamente na decisão das partes por meio de sugestões, opiniões ou conselhos. (ALMEIDA e RODRIGUES JÚNIOR: 2010, p.598).

Nesse contexto, a mediação teria inclusive o papel de estimular o alienador e o alienado ao diálogo, buscando o bem da criança ou do adolescente. Apenas punir o alienador não garante o direito à convivência familiar. É necessário que se trabalhe o alienador para que este possa ser também um agente promotor da convivência familiar e não que seja alijado da vida da pessoa em desenvolvimento. Para Ignacio Bolaños Cartujo (2000), a mediação além de facilitar a comunicação teria um importante papel na criação de um contexto cooperativo capaz de transformar aquela situação conflitiva.

Merecia aplausos a redação do artigo $9^{\circ}$ do projeto de lei que deu origem a Lei n.12.318/2010, que facultava o uso da mediação judicial ou extrajudicial como solução para acabar com a Alienação Parental. O dispositivo foi assim redigido:

Art. $9^{\circ}$ As partes, por iniciativa própria ou sugestão do juiz, do Ministério Público ou do Conselho Tutelar, poderão utilizar-se do procedimento da mediação para a solução do litígio, antes ou no curso do processo judicial.

$\S 1^{\circ} \mathrm{O}$ acordo que estabelecer a mediação indicará o prazo de eventual suspensão do processo e o correspondente regime provisório para regular as questões controvertidas, o qual não vinculará eventual decisão judicial superveniente.

$\S 2^{\circ} \mathrm{O}$ mediador será livremente escolhido pelas partes, mas o juízo competente, o Ministério Público e o Conselho Tutelar formarão cadastros de mediadores habilitados a examinar questões relacionadas à alienação parental.

$\S 3^{\circ} \mathrm{O}$ termo que ajustar o procedimento de mediação ou o que dele resultar deverá ser submetido ao exame do Ministério Público e à homologação judicial.

Sendo o propósito da lei não só atacar a AP, mas, em primeiro lugar, promover o bem-estar e o direito fundamental da criança e do adolescente ao seu desenvolvimento sadio, com a utilização da mediação poderia se atingir os dois objetivos. 
No entanto, esse não foi o entendimento da Presidência da República. O dispositivo foi vetado sob as justificativas de que não caberia a apreciação do Direito à Convivência Familiar de crianças e de adolescentes por mecanismos autocompositivos de solução de conflitos e que a Lei n. 8.069/1990 prevê a aplicação do princípio da intervenção mínima, segundo o qual eventual medida para a proteção da criança e do adolescente deve ser exercida exclusivamente pelas autoridades e instituições cuja ação seja indispensável. (BRASIL, 2010b)

As justificativas apresentadas demonstram total desconhecimento de todo o sistema protetivo da criança e do adolescente.

Conforme ressaltado na mensagem de veto n. 513/2010, o Direito à Convivência Familiar de crianças e adolescentes é indisponível. Todavia, não significa que nenhuma forma alternativa de resolução de conflitos possa ser utilizada. Deve-se ressaltar que de acordo com as razões informadas na mensagem de veto presidencial, apenas a mediação extrajudicial é que não deveria ser utilizada, não havendo objeção alguma a mediação judicial. No entanto, o novo Código de Processo Civil, Lei n. 13.015/2015, que entrará em 2016, em seu artigo 695, dá especial destaque a conciliação e a mediação, determinando a realização de uma audiência própria para se tentar utilizar essas metodologias autocompositivas e prevendo a possibilidade de suspensão do processo, caso as partes se submetam a mediação extrajudicial ou ao atendimento multidisciplinar (art. 694, parágrafo único). Apesar da ação autônoma para declaração de Alienação Parental não constar no rol das ações de família previstas no artigo 693 do novo Código de Processo Civil, espera-se que uma interpretação extensiva seja dada ao dispositivo.

Todavia, também o segundo argumento não parece justificar o veto. O princípio da intervenção mínima foi previsto exclusivamente para a aplicação das medidas protetivas previstas no art. 101, conforme redação expressa do caput do art. 100 da Lei. O Conselho Tutelar é um desses órgãos ou instituições que legitimados a agir cabendo a ele aplicar, também, as medidas previstas no artigo 101, I a VII da Lei n. 8.069/1990. Logo, se o Conselho Tutelar pudesse promover a mediação não haveria necessidade de se provocar o judiciário, estando aí efetivado o princípio da intervenção mínima.

\section{O TRIBUNAL DE JUSTIÇA DE MINAS GERAIS E A ALIENAÇÃO PARENTAL}


Feitas as considerações sobre a Lei n. 12.318/2010, faz-se necessário pesquisar as modificações por ela provocadas no judiciário brasileiro. Optou-se por examinar as decisões proferidas em $2^{\mathrm{a}}$ instância pelo Tribunal de Justiça de Minas Gerais (TJMG), vez que o acesso a decisões de $1^{\text {a }}$ instância é restrito em razão da não existência de um banco de dados disponível ao público.

A pesquisa foi realizada no sítio eletrônico do TJMG (www.tjmg.jus.br) na seção "Jurisprudência" utilizando a ferramenta "Pesquisa Por Acórdãos", e as palavras utilizadas para a realização da busca foram: "alienação parental". Até o dia 9 de agosto de 2015 havia 79 acórdãos no banco de dados do referido sítio, tendo sido todos analisados em período de 2 meses $^{17 .}$

As decisões localizadas foram divididas pelo tipo de instrumento processual que ensejou a manifestação do TJMG e do ano de prolação do acórdão. Das 79 decisões, 53 delas foram proferidas em julgamento de Agravo de Instrumento (Ag), 22 em sede de recurso de Apelação Cível (AC), 3 em recurso de Embargos de Declaração (ED) e 1 em julgamento de Conflito de Competência (CC). Na divisão por ano de manifestação, apenas uma vez a expressão "Alienação Parental" foi mencionada em uma decisão em 2009, enquanto a mesma expressão apareceu por 6 vezes em 2010, 22 em 2011 e 7 em 2012 nos acórdãos do TJMG. Já em 2013, em 14 ocasiões uma decisão do referido tribunal citou a “Alienação Parental”, tendo esse número subido para 23 em 2014. Até o início de agosto de 2015, por 6 vezes "Alienação Parental" foi mencionada nos julgamentos do TJMG. Os resultados foram sintetizados na tabela abaixo.

\begin{tabular}{|c|c|c|c|c|c|}
\hline Ano & AC & Ag & ED & CC & Total \\
\hline 2009 & 1 & -- & -- & -- & 1 \\
\hline 2010 & 3 & 3 & -- & -- & 6 \\
\hline 2011 & 3 & 18 & 1 & -- & 22 \\
\hline 2012 & 3 & 4 & -- & -- & 7 \\
\hline 2013 & 5 & 9 & -- & -- & 14 \\
\hline 2014 & 5 & 16 & 1 & 1 & 23 \\
\hline 2015 & 2 & 3 & 1 & - & 6 \\
\hline Total & 22 & 53 & 3 & 1 & 79 \\
\hline
\end{tabular}

\footnotetext{
${ }^{17}$ A primeira pesquisa foi realizada em março de 2015 e registrou setenta e quatro decisões. A mesma pesquisa foi repetida várias vezes até o dia nove de agosto, e, ao longo dos dois meses de trabalho, novos acórdãos foram acrescentados ao banco de dados do sítio do TJMG e foram também analisados.
} 
A preponderância dos acórdãos prolatados em recurso de Agravo de Instrumento é compreensível, tendo em vista a urgência em se "atacar" uma decisão que verse sobre Alienação Parental, uma vez que, como já tratado, esta é uma violação aos direitos infantojuvenis e como tal deve ser o mais rapidamente coibida.

Analisando os resultados obtidos, nota-se que antes mesmo do advento de Lei n. 12.318/2010, o TJMG já se mostrava atento à questão, uma vez que em seis julgados ${ }^{18}$ se encontra a expressão “Alienação Parental”. Interessante apontar que desses seis acórdãos, quatro deles citam "Síndrome da Alienação Parental”, e não "Alienação Parental”, cujas diferenças já foram abordadas ao longo deste trabalho. Isso se deve a duas circunstâncias: 1) os primeiros juristas brasileiros a apontar a questão, entre eles a advogada Maria Berenice Dias $^{19}$, trabalhavam com a patologia SAP, e não com o conceito mais amplo de AP, e 2) a opção do Direito nacional pela AP só foi feita na Lei n. 12.318/2010. No entanto, a expressão "Síndrome da Alienação Parental" só vem a ser novamente encontrada em outras cinco decisões, sendo três prolatadas em 2011, uma em 2012 e uma em 2014.

Observa-se também que, ao contrário do que poderia se pensar, não houve um aumento gradativo de pronunciamentos do tribunal mineiro sobre o tema. Isso porque, apesar de ter ocorrido um salto do número dos julgados que tratam do assunto em 2011 (22 contra somente 6 registros no ano anterior), no ano seguinte apenas 7 acórdãos citam "Alienação Parental". Nos anos de 2013 e 2014, acórdãos que versam sobre a temática se tornaram mais frequentes (14 e 23, respectivamente). É possível que esse número venha a cair em 2015, uma vez que até agosto deste ano foram encontradas 6 menções à "Alienação Parental", enquanto até o mesmo mês do ano passado já havia 17 julgados que citavam o termo.

Quando se examina a quem se atribui a prática da AP, nota-se que em 56 dos 79 julgados um dos pais é apontado como o responsável por prejudicar a convivência da criança e/ou do adolescente com o outro genitor. Já em outros 10 acórdãos, outro familiar foi apontado como alienador, sendo os avós em 9 deles e os tios em um único julgado. Nas outras 13 decisões não foi possível identificar o suposto causador da AP, seja porque não ficou claro no teor do acórdão, seja porque a discussão do recurso versava sobre questões processuais. Distribuindo esses dados por ano de julgamento dos acórdãos, tem-se:

\footnotetext{
18 Quatro dos seis acórdãos que mencionam “Alienação Parental” em 2010 foram proferidos antes de 26 de agosto daquele ano, data em que a Lei n. 12.318/2010 foi publicada e entrou em vigor.

${ }^{19}$ Examinando os setenta e nove acórdãos, Maria Berenice Dias é a jurista mais citada nos julgados mineiros, o que demonstra a importância da advogada gaúcha no desenvolvimento do tema no Brasil.
} 


\begin{tabular}{|c|c|c|c|c|}
\hline & Pai ou Mãe & Outros familiares & $\begin{array}{c}\text { Não se identificou } \\
\text { ou não se aplica }\end{array}$ & Total \\
\hline 2009 & 1 & -- & -- & 1 \\
\hline 2010 & 5 & -- & 2 & 7 \\
\hline 2011 & 13 & 5 & 3 & 21 \\
\hline 2012 & 4 & 2 & 1 & 7 \\
\hline 2013 & 11 & 1 & 2 & 14 \\
\hline 2014 & 16 & 2 & 5 & 23 \\
\hline 2015 & 6 & -- & -- & 6 \\
\hline Total & 56 & 10 & 13 & 79 \\
\hline
\end{tabular}

Apesar de ser esperada essa absoluta predominância dos casos em que se atribui a um dos pais a prática de atos de Alienação Parental, chama atenção a decisão na qual se reconheceu a AP praticada tanto pelo pai quanto pela tia da criança ${ }^{20}$ e outros dois julgados em que foi reconhecido que um dos avós praticou atos de Alienação Parental contra ambos os genitores ${ }^{21}$. Dentro daquelas decisões classificadas como "não se aplica", duas delas se referem ao julgamento de apelações cíveis em ações de investigação de paternidade prevista na Lei n. 8.560/1992, nas quais as genitoras se recusaram a informar os nomes dos pais biológicos de seus filhos perante o oficial do cartório de registro civil. Curiosamente, ambos os julgados foram não unânimes, e no primeiro deles a tese de que a negativa da mãe biológica em indicar o nome do suposto genitor poderia se caracterizar AP foi vencida, enquanto no segundo acordão ela foi vencedora ${ }^{22}$.

Os julgados também foram analisados quanto ao pronunciamento do TJMG, especificamente em relação à Alienação Parental, tendo sido eles classificados em quatro categorias: reconhece, não reconhece, indícios e não se aplica ou se discute. No primeiro grupo foram enquadrados todos os acórdãos nos quais foi reconhecida a prática de atos de Alienação Parental, seja pela $1^{\mathrm{a}}$ ou pela $2^{\mathrm{a}}$ instância, tendo sido ou não aplicada alguma medida prevista na Lei n. 12.318/2010 também em qualquer das instâncias do judiciário. $\mathrm{Na}$

20 TJMG. Ag. 1.0281.09.014724-6/002, 7ª Câmara Civil, Des. Relator Belizário Lacerda, julgado em 25 de outubro de 2011 .

21 TJMG. AC. 1.0016.10.001579-7/001, 4ª Câmara Civil, Des. Relator Audebert Delage, julgado em 12 de fevereiro de 2012 e Ag. 1.0395.11.000387-2/003, 2a Câmara Cível, Des. Relator Afrânio Vilela, julgado 6 de maio de 2014.

${ }^{22}$ TJMG. AC. 1.0382.11.015130-7/001, 2 a Câmara Civil, Des. Relator Caetano Levi Lopes, julgado em 11 de setembro de 2012 e AC. 1.0188.12.008409-3/001, 8ª Câmara Cível, Des. Relator Alyrio Ramos, julgado 3 de julho de 2014, respectivamente. Essas decisões foram enquadradas na categoria "não se aplica" em razão de não constar nas decisões elementos para afirmar que a mãe efetivamente sabia quem era o pai biológico de seu filho ou se ele é vivo. Ademais, tal situação parece bem distante daquelas em que até hoje se reconheceu a AP, uma 
segunda categoria ficaram os julgados em que não houve o reconhecimento pelo Juiz ou pelos desembargadores dos atos de AP, seja pela ausência de provas ou pela inexistência de ato violador de direitos. Já na terceira classe foram reunidas todas as decisões em que há indícios ainda não cabalmente comprovados da ocorrência da prática de Alienação Parental. Por fim, no último grupo estão todos os acórdãos que, embora em algum momento se mencione a expressão "Alienação Parental", não há de fato uma discussão sobre a sua ocorrência, sendo normalmente debatida alguma questão de cunho processual. No primeiro grupo há 24 julgados, enquanto na segunda e na terceira categoria há 27 e 14 decisões, respectivamente, restando 14 acórdãos na quarta classe, como demonstra a tabela abaixo:

\begin{tabular}{|c|c|c|c|c|c|}
\hline & Reconhece & Não reconhece & Indícios & $\begin{array}{c}\text { Não se aplica ou se } \\
\text { discute }\end{array}$ & Total \\
\hline 2009 & 1 & -- & -- & -- & 1 \\
\hline 2010 & 1 & 2 & 2 & 2 & 7 \\
\hline 2011 & 5 & 8 & 5 & 3 & 21 \\
\hline 2012 & 2 & 3 & 1 & 1 & 7 \\
\hline 2013 & 5 & 6 & 1 & 2 & 14 \\
\hline 2014 & 7 & 7 & 3 & 6 & 23 \\
\hline 2015 & 3 & 1 & 2 & -- & 6 \\
\hline Total & 24 & 27 & 14 & 14 & 79 \\
\hline
\end{tabular}

Verifica-se, portanto, que o TJMG está atento à Alienação Parental, reconhecendo sua prática em 24 casos e a ocorrência de indícios em mais 14 julgados, perfazendo um total de 38 decisões, o que corresponde a cerca de 48 por cento dos acórdãos. Sobre os indícios, é importante esclarecer que, como já trabalhado, a grande maioria das decisões se referem a julgamento de Agravos de Instrumento, sendo que parte deles é recurso interposto antes da realização da prova técnica definitiva. Dentro dos julgados que reconhecem a existência de indícios da prática de AP, destaca-se a única decisão prolatada por uma câmara criminal encontrada na pesquisa. Tal decisão foi proferida em sede de Embargos de Declaração interpostos em face de decisão que não acolheu os Embargos Infringentes, não se manifestando sobre provas juntadas após o julgamento do recurso de apelação que condenou o réu a nove anos de reclusão pelo crime de estupro de vulnerável, supostamente praticado

vez que se pensa primeiramente em um laço paterno/materno filial existente que posteriormente passa a ser obstaculizado por alguém. 
pelo pai contra a filha, provas essas (relatórios sociais e psicológicos até então confidenciais) que trouxeram fortes indícios de Alienação Parental, colocando em dúvida o depoimento da criança que servia de base para a condenação. $\mathrm{O}$ acórdão conferiu efeitos infringentes ao ED sanando a omissão, isto é, analisando a prova técnica e mantendo a sentença de $1^{\mathrm{a}}$ instância que absolveu o pai ${ }^{23}$.

Das 24 decisões que atestam a ocorrência da AP, 14 delas apenas reconhecem a prática da Alienação Parental, enquanto outras 7 vão além e também aplicam algumas das medidas previstas no artigo $6^{\circ}$ da Lei n. 12.318/2010.

\begin{tabular}{|c|c|c|c|}
\hline & Reconhece & $\begin{array}{c}\text { Reconhece e aplica } \\
\text { medida }\end{array}$ & Total \\
\hline 2009 & 1 & -- & 1 \\
\hline 2010 & 1 & -- & 1 \\
\hline 2011 & 5 & -- & 5 \\
\hline 2012 & 2 & -- & 2 \\
\hline 2013 & 3 & 2 & 5 \\
\hline 2014 & 4 & 3 & 7 \\
\hline 2015 & 1 & 2 & 3 \\
\hline Total & 17 & 7 & 24 \\
\hline
\end{tabular}

A não aplicação de medidas sancionatórias em 2009 e 2010 é explicada pelo fato de a Lei n. 12.318/2010 não estar em vigor em grande parte desse período. Nota-se que os registros nos acórdãos de imposição das sanções previstas na referida lei só começam a ocorrer a partir de 2013, sendo aplicadas somente as medidas de advertência, multa, acompanhamento psicológico e modificação de guarda (art. $6^{\circ}$ I, III, IV e V). Um dos julgados que modificou o regime de guarda concedendo-a ao pai em razão da comprovação dos atos de AP praticados pela genitora, aponta para a necessidade de também se preservar o convívio da criança com a mãe alienadora, não restringindo o contato materno-filial a um mínimo como pretendia o genitor ${ }^{24}$.

Examinando as decisões em que não reconheceram a Alienação Parental, nota-se que em 10 delas houve a declaração expressa de sua não ocorrência, e nas outras 17 restantes o TJMG se manifestou pela ausência de provas.

${ }^{23}$ TJMG. ED. 1.0024.06.150046-8/003, $1^{\text {a }}$ Câmara Criminal, Des. Relator Alberto Deodato Neto, julgado em 03 de fevereiro de 2014.

${ }^{24}$ TJMG. AC. 1.0024.09.725125-0/014, 5 Câmara Cível, Des. Relator Barros Levenhager, julgado em 20 de março de 2014. 


\begin{tabular}{|c|c|c|c|}
\hline & $\begin{array}{c}\text { Não reconhece } \\
\text { expressamente }\end{array}$ & Sem provas & Total \\
\hline 2009 & -- & -- & -- \\
\hline 2010 & -- & 2 & 2 \\
\hline 2011 & 2 & 6 & 8 \\
\hline 2012 & 1 & 2 & 3 \\
\hline 2013 & 4 & 2 & 6 \\
\hline 2014 & 3 & 4 & 7 \\
\hline 2015 & -- & 1 & -- \\
\hline Total & 10 & 17 & 27 \\
\hline
\end{tabular}

Os desembargadores do TJMG têm ressaltado em diversos julgados a relação de animosidade entre os pais, sendo que, talvez por essa razão, eles se mostram cautelosos na análise das provas existentes nos autos, tanto para afirmarem que houve quanto que não houve atos de Alienação Parental. A prova técnica é sempre exigida, e quando não há a comprovação cabal da AP, o TJMG tem reiteradamente se manifestado pela não existência de provas ou de indícios de provas.

De todos os acórdãos analisados, pode-se afirmar que a partir de 2010 o TJMG tem enfrentado com mais frequência a Alienação Parental, que, embora já existisse antes, passa a ganhar uma delimitação jurídica, facilitando sua identificação e sua coibição. Todavia, as decisões têm se mostrado bastante casuísticas, não sendo possível visualizar com clareza tendências da corte sobre a temática.

\section{CONCLUSÃO}

A sociedade brasileira avança no objetivo de se proteger a população infantojuvenil e tentar fazer com que a família se torne aquele espaço ideal para o desenvolvimento da personalidade de seus componentes, como defendem partes dos estudiosos de Direto de Família no país.

Este trabalho procurou abordar uma situação que pode atrapalhar tanto a formação da personalidade de crianças e de adolescentes, quanto a harmonia nas relações familiares, especialmente na relação entre pais e filhos: a Alienação Parental. 
Para se compreender melhor o tema, é preciso que se tenha uma concepção de Direito à Convivência Familiar que vai além da mera visitação, abrangendo a efetiva participação infantojuvenil no dia a dia da família. Só a partir dessa compreensão é possível se entender a dimensão dos efeitos prejudiciais da Alienação Parental.

Distanciando da patologia Síndrome da Alienação Parental, o Direito nacional buscou combater a AP, que seria uma violação mais ampla dos direitos da criança e do adolescente e englobaria a SAP. Nesse contexto, o advento da Lei n. 12.318/2010 representa um inegável ganho para a proteção do Direito à Convivência Familiar de crianças e de adolescentes. Ela chama atenção para uma situação que há muito prejudica o desenvolvimento dos laços materno-paterno filiais, trazendo grandes prejuízos a formação da personalidade infantojuvenil. Ao prever quem legalmente podem ser considerados alienadores, exemplificar quais condutas seriam consideradas atos de AP e elencar quais medidas são aplicáveis aqueles que as perpetrarem, a referida lei mune o magistrado de critérios objetivos para que ele possa atuar com segurança buscando eliminar os nefastos efeitos dessa verdadeira violação dos direitos de crianças e de adolescentes.

A pesquisa feita no sítio eletrônico do Tribunal de Justiça de Minas Gerais nos possibilitou ver como a cúpula do Judiciário mineiro está enfrentando a questão e comprovar que a ampliação no rol dos possíveis alienadores foi de fato benéfica, uma vez que permitiu a aplicação da Lei n. 12.318/2010 a outros familiares. No entanto, ainda é cedo para se extrair entendimentos consolidados da corte estadual sobre o tema.

Todavia, o avanço poderia ser maior se o legislador tivesse um pensamento mais amplo, se preocupando não só em sancionar o alienador, mas sim de trabalhar para prevenir e tratar os reflexos da Alienação Parental, promovendo a real proteção integral da criança. Esperamos que o novo Código de Processo Civil seja visto como uma possibilidade de se corrigir essa fragilidade identificada na lei específica.

\section{REFERÊNCIAS}

ALMEIDA, Renata Barbosa de e RODRIGUES JÚNIOR, Walsir Édson. Direito Civil Famílias. Rio de Janeiro-RJ: Lúmen Júris.

AZAMBUJA, Maria Regina Fay de, TELLES, Lisieux E. de Borba; DAY, Vivian Peres. A alienação parental à luz do Direito da Criança. Disponível em: <https://www.mprs.mp.br/infancia/doutrina/id751.htm>. Acesso em 23 jul. 2015. 
BRASIL. Constituição (1988). Constituição da República Federativa do Brasil de 1988. Brasília: $\quad$ Senado, $1988 . \quad$ Disponível em: <http://www.planalto.gov.br/ccivil_03/constituicao/constitui\%C3\%A7ao.htm>. Acesso em 07 jul. 2015.

BRASIL. Lei $\mathbf{n}^{\mathbf{0}}$ 8.069, de 13 de julho de 1990. Dispõe sobre o Estatuto da Criança e do Adolescente e dá outras providências. Disponível em <http://www.planalto.gov.br/ccivil_03/leis/L8069.htm>. Acesso em 22 jul. 2015.

BRASIL. Lei $\mathbf{n}^{\circ}$ 10.406, de 10 de janeiro de 2002. Institui o Código Civil. Disponível em: < http://www.planalto.gov.br/ccivil_03/leis/2002/L10406.htm>. Acesso em 12 jun. 2015.

BRASIL. Lei $\mathbf{n}^{\circ}$ 12.318, de 26 de agosto de 2010. Dispõe sobre alienação parental. Disponível em: <http://www.planalto.gov.br/ccivil_03/_Ato20072010/2010/Lei/L12318.htm>. Acesso em 12 jun. 2015.

BRASIL. Mensagem $n^{\circ}$ 513, de 26 de ago. de 2010. Disponível em: <http://www.planalto.gov.br/ccivil_03/_Ato2007-2010/2010/Msg/VEP-513-10.htm>. Acesso em 13 jun. 2015.

BOLAÑOS CARTUJO, Ignacio. Estudio Descriptivo del Síndrome de Alienación Parental en procesos de separación y divorcio. Diseño y aplicación de un programa piloto en mediación familiar. 2000. 344f. Tese (Doutorado) - Universitat Autònoma de Barcelona. Facultat de Psicologia. Barcelona, 2000.

DIAS, Maria Berenice. Manual de Direito das Famílias. 4ª Edição Revista, atualizada e ampliada. São Paulo: Ed. Revista dos Tribunais, 2007.

Síndrome da Alienação parental. O que é isso? Disponível em: <http://www.mariaberenice.com.br/uploads/1_-_s\%EDndrome_da_aliena\%E7\%E3o parental\%2C_o_que_\%E9_isso.pdf>. Acesso em 14 jul. 2015.

GONDIN, Frederick. Alienação Parental: a impropriedade do inciso III do $\operatorname{artigo~} 6^{\circ}$ da Lei $n^{0}$ 12.318, de 26 de agosto de 2010 (Lei da Alienação Parental). Disponível em: $<$ http:// http://www.direitonet.com.br/artigos/exibir/7064/Alienacao-parental-aimpropriedade-do-inciso-III-do-artigo-6o-da-lei-n-12318-2010>. Acesso em: 17 jul. 2015.

HIRONAKA, Giselda Maria Fernandes Novaes; MONACO, Gustavo Ferraz de Campos. Síndrome de alienação parental. TEIXEIRA, Ana Carolina Brochado et al. (Coord.) Problemas da Família no Direito. Belo Horizonte: Del Rey, 2011.

LONDOÑO, Fernando Torres. A origem do conceito menor. In: PRIORE, Mary Del (org.). História da criança no Brasil. São Paulo: Ed. Contexto, 1996.

MILAGRES, Marcelo de Oliveira. Normas cogentes e dispositivas de direito de família. Revista de Direito Privado. v. 35. São Paulo: Revista dos Tribunais, 2008, jul/set., p. 211 228.

MINAS GERAIS. Tribunal de Justiça. Processo: AG. 1.0281.09.014724-6/002. Relator: Belizário Lacerda. Belo Horizonte, 25 out., 2011. Disponível em: 
<http://www5.tjmg.jus.br/jurisprudencia/pesquisaNumeroCNJEspelhoAcordao.do?numeroRe gistro $=1 \&$ totalLinhas $=1 \&$ linhasPorPagina $=10 \&$ numeroUnico $=1.0281 .09 .014724-$ 6\%2F002\&pesquisaNumeroCNJ=Pesquisar> Acesso em: 05 ago. 2015.

MINAS GERAIS. Tribunal de Justiça. Processo: AC. 1.0016.10.001579-7/001. Relator: Audebert Delage. Belo Horizonte, 12 fev., 2012. Disponível em: <http://www5.tjmg.jus.br/jurisprudencia/pesquisaNumeroCNJEspelhoAcordao.do?numeroRe gistro $=1$ \& totalLinhas $=1$ \&linhasPorPagina $=10 \&$ numeroUnico $=1.0016 .10 .001579$ -

7\%2F001\&pesquisaNumeroCNJ=Pesquisar> Acesso em: 05 ago. 2015.

MINAS GERAIS. Tribunal de Justiça. Processo: AG. 1.0395.11.000387-2/003. Relator: Afrânio Vilela. Belo Horizonte, 6 mai., 2014. Disponível em: <http://www5.tjmg.jus.br/jurisprudencia/pesquisaNumeroCNJEspelhoAcordao.do?numeroRe gistro=1\&totalLinhas $=1 \&$ linhasPorPagina $=10 \&$ numeroUnico=1.0395.11.0003872\%2F003\&pesquisaNumeroCNJ=Pesquisar> Acesso em: 05 ago. 2015.

MINAS GERAIS. Tribunal de Justiça. Processo: AC. 1.0382.11.015130-7/001. Relator: Caetano Levi Lopes. Belo Horizonte, 12 set., 2012. Disponível em: <http://www5.tjmg.jus.br/jurisprudencia/pesquisaNumeroCNJEspelhoAcordao.do?numeroRe gistro $=1 \&$ totalLinhas $=1 \&$ linhasPorPagina $=10 \&$ numeroUnico=1.0382.11.015130-

7\%2F001\&pesquisaNumeroCNJ=Pesquisar $>$ Acesso em: 05 ago. 2015.

MINAS GERAIS. Tribunal de Justiça. Processo: AC. 1.0188.12.008409-3/001. Relator: Alyrio Ramos. Belo Horizonte, 3 jul., 2014. Disponível em: <http://www5.tjmg.jus.br/jurisprudencia/pesquisaNumeroCNJEspelhoAcordao.do?numeroRe gistro $=1$ \& totalLinhas $=1$ \&linhasPorPagina $=10$ \&numeroUnico=1.0188.12.0084093\%2F001\&pesquisaNumeroCNJ=Pesquisar> Acesso em: 05 ago. 2015.

MINAS GERAIS. Tribunal de Justiça. Processo: ED. 1.0024.06.150046-8/003. Relator: Alberto Deodato Neto. Belo Horizonte, 3 fev., 2015. Disponível em: <http://www5.tjmg.jus.br/jurisprudencia/pesquisaNumeroCNJEspelhoAcordao.do?numeroRe gistro $=1 \&$ totalLinhas $=1$ \&linhasPorPagina $=10 \&$ numeroUnico=1.0024.06.1500468\%2F003\&pesquisaNumeroCNJ=Pesquisar $>$ Acesso em: 05 ago. 2015.

MINAS GERAIS. Tribunal de Justiça. Processo: AG. 1.0024.09.725125-0/014. Relator: Barros Levenhagen. Belo Horizonte, 20 mar., 2014. Disponível em: <http://www5.tjmg.jus.br/jurisprudencia/pesquisaNumeroCNJEspelhoAcordao.do?numeroRe gistro $=1 \&$ totalLinhas $=1 \&$ linhasPorPagina $=10 \&$ numeroUnico $=1.0024 .09 .725125$ 0\%2F014\&pesquisaNumeroCNJ=Pesquisar> Acesso em: 05 ago. 2015.

MOTTA, Maria Antonieta Pisano. A Síndrome da alienação parental. In: ASSOCIAÇÃO DE PAIS E MÃES SEPARADOS. Síndrome da alienação parental e a tirania do guardião: Aspectos psicológicos, sociais e jurídicos. Porto Alegre: Equilíbrio, 2008.

NERY JÚNIOR, Nelson; MACHADO, Martha de Toledo. O Estatuto da Criança e do Adolescente e o Novo Código Civil à luz da Constituição Federal: Princípio da Especialidade e Direito Intertemporal. Disponível em: <http://jij.tj.rs.gov.br/jij_site/docs/DOUTRINA/NELSONMARTHA.HTM>. Acesso em 13 fev. 2013. 
PEREIRA, Tânia da Silva. Direito da Criança e do Adolescente: uma proposta interdisciplinar. $2^{\text {a }}$ Ed. Revista e atualizada. Rio de Janeiro: Renovar, 2008.

SAP - SINDROME DA ALIENAÇÃO PARENTAL. O que é SAP? <http://www.alienacaoparental.com.br/o-que-e>. Acesso em 14 jul. 20105.

SILVA, Evandro Luiz, RESENDE, Mário. SAP: A Exclusão de um terceiro. In: ASSOCIAÇÃO DE PAIS E MÃES SEPARADOS. Síndrome da alienação parental e a tirania do guardião: Aspectos psicológicos, sociais e jurídicos. Porto Alegre: Equilíbrio, 2008.

SIMÃO, Rosane Barbosa Cipriano. Soluções judiciais concretas contra a perniciosa prática da alienação parental. In: ASSOCIAÇÃO DE PAIS E MÃES SEPARADOS. Síndrome da alienação parental e a tirania do guardião: Aspectos psicológicos, sociais e jurídicos. Porto Alegre: Equilíbrio, 2008.

TEIXEIRA, Ana Carolina Brochado. A (des) necessidade da guarda compartilhada ante o conteúdo da autoridade parental. In: TEIXEIRA, Ana Carolina Brochado e RIBEIRO, Gustavo Pereira Leite (Coord.). Manual de Direito das Famílias e das Sucessões. Belo Horizonte: Del Rey: Mandamentos, 2008. p. 301-319.

VALENTE, Maria Luiza Campos da Silva. Síndrome da alienação parental: a perspectiva do serviço social. In: ASSOCIAÇÃO DE PAIS E MÃES SEPARADOS. Síndrome da alienação parental e a tirania do guardião: Aspectos psicológicos, sociais e jurídicos. Porto Alegre: Equilíbrio, 2008.

VIEIRA, Marcelo de Mello. O Direito da Personalidade à Convivência Familiar de crianças e adolescentes. Diké - Revista Eletrônica de Direito, Filosofia e Política do Curso de Direito da Unipac de Itabirito, v. 4, p. 127-140, 1o semestre 2012. 